ISSN 2549-6018 (online)

ISSN 1907-7513 (Print)

\title{
Implementasi Electronic Data Processing Pada Koperasi Wanita
}

\author{
Rita Mutiarni \\ STIE PGRI Dewantara Jombang \\ *Korespondensi: rita.dewantara@gmail.com
}

Diserahkan: 28 Mei 2017, Direvisis: 14 Juli 2017 Diterima: 31 Agustus 2017

\begin{abstract}
The research conducted on Women Cooperative in Jombang aims to: Know the distribution of Women's Cooperative in Jombang that organizes the recording of computerized transactions (Electronic Data Processing), to know the application of Electronic Data Processing - EDP and Supporting Factors of Successful Electronic Data Processing - EDP in Women's Cooperative Jombang regency; Find out if the EDP and Supporting Factors for Successful Electronic Data Processing - EDP against the management decision of the Cooperative. The type of research is qualitative research, involving 19 respondents as research sample. From the research results it is known that: Of 306 female cooperatives scattered in 21 districts in Jombang regency, not all are in active condition. For 2017, as many as 70 female cooperatives or 23\%, until June, have not yet held Annual Member Meetings, There are 19 female cooperatives or 6\% who use computers to help record transactions. Application of Electronic Data Processing and Factors supporting the successful implementation of Electronic Data Processing in Koperasi Wanita Jombang district is good,Variable Electronic Data Processing and Supporting Factors Successful Implementation of Electronic Data Processing affects the management decision of Cooperative.
\end{abstract}

Keywords: Implementation, EDP, Cooperative, Women.

\begin{abstract}
Abstrak
Penelitian yang dilakukan pada Koperasi Wanita di Jombang ini bertujuan untukMengetahui sebaran Koperasi di Jombang yang menyelenggarakan pencatatan transaksi secara komputerisasi (Electronic Data Processing), mengetahui penerapan unsur-unsur Electronic Data Processing dan Faktor Pendukung Kesuksesan Pelaksanaan Electronic Data Processing di Koperasi Wanita kabupaten Jombang, Mengetahui apakah variabel EDP dan Faktor Pendukung Kesuksesan Pelaksanaan Electronic Data Processing berpengaruh terhadap keputusan manajemen Koperasi. Jenis penelitian adalah penelitian kualitatif, dengan melibatkan 19 responden sebagai sampel penelitian. Dari hasil penelitian diketahui bahwa Dari 306 Koperasi Wanita yang tersebar di 21 kecamatan di kabupaten Jombang, tidak semuanya dalam kondisi aktif. Untuk tahun 2017, sebanyak 70 Koperasi Wanita atau 23\%, sampai bulan Juni, belum melakukan Rapat Anggota Tahunan, Ada 19 Koperasi Wanita (kopwan) atau 6\% yang menggunakan komputer untuk membantu pencatatan transaksinya. Penerapan Electronic Data Processing dan Faktor pendukung kesuksesan pelaksanaan Electronic Data Processing di Koperasi Wanita kabupaten Jombang sudah baik, Variabel Electronic Data Processing dan Faktor Pendukung Kesuksesan Pelaksanaan Electronic Data Processing berpengaruh terhadap keputusan manajemen Koperasi.
\end{abstract}

Kata kunci: Implementasi, EDP, Koperasi, Wanita.

\section{A. Pendahuluan}

Ditengah gencarnya persaingan dunia usaha, masyarkat dituntut untuk meningkatkan mutu sumber daya dengan lebih aktif dan kreatif. Pemeritah Jombang, terus melakukan pembinaan pada lembaga yang berbasis perekonomian rakyat seperti koperasi, dengan memberikan pelatihan tentang akuntansi dan manajemen koperasi (Zakaria, 2016). 
Undang-Undang Dasar 1945 khususnya Pasal 33 ayat (I) menyatakan bahwa kemakmuran masyarakat yang diutamakan bukan kemakmuran orang-seorang dan bangun perusahaan yang sesuai dengan itu adalah koperasi. Penjelasan Pasal 33 menempatkan koperasi dalam kedudukan sebagai sokoguru perekonomian nasional dan sebagai bagian integral tata perekonomian nasional Koperasi (Partomo, 2009: 15).

Peran koperasi dipandang sangat sesuai dan strategis untuk ikut menopang ekonomi rakyat, terutama masalah pendanaan yang saat ini sangat dibutuhkan sebagai usaha pemerintah untuk mengembangkan usaha mikro, kecil dan menengah (Partomo, 2009:71). Apabila koperasi dikelola dengan baik akan mampu mensejahterakan anggotanya dan bisa melaksanakan RAT (Yusuf, 2015). Pemberdayaan koperasi akan mendukung peningkatan produktivitas, penyediaan lapangan kerja yang lebih luas, dan peningkatan pendapatan bagi masyarakat miskin (Tartini \& Zulkifli, 2016).

Perkembangan koperasi di Jawa Timur yang jumlahnya pada tahun 2014 mencapai 30.866 koperasi $34 \%$ nya didominasi oleh koperasi wanita/Koperasi Wanita (kopwan) (Suara Mandiri, 2015). Anggota koperasi tersebut terdiri dari Usaha Mikro Kecil dan Menengah (UMKM) yang menurut data sensus UMKM mampu menyumbang 54, 48\% PDRB Jawa Timur.

Di Kota Jombang, sesuai data tahun 2015, terdapat 325 koperasi sehat, 766 koperasi aktif dan 55 koperasi tidak aktif. Untuk Koperasi Wanita (kopwan), sudah tersebar di 21 kecamatan yang berada dari 301 desa dan 5 kelurahan. Sedangkan Data tahun 2015 menunukkan bahwa 93,36\% wanita di Jawa Timur adalah muslimah (Suara Madiri, 2015), maka pemberdayaan melaui Koperasi Wanita (kopwan) sangatlah tepat. Melalui kopwankopwan tersebut akan mampu mewujudkan kopwan syariah. Sejalan dengan geliat ekonomi syariah yang pesat selama dua tahun terakhir, utamanya dengan dipilihnya Jawa Timur sebagai contoh penerapan ekonomi syariah. Hal ini sejalan dengan tujuan pemerintah yang ingin memberdayakan wanita (Budhiretnowati \& Siahaa, 2015). Dalam usaha meningkatkan kesejahteraan masyarakat (Yuni Nurmawati, Y,2015). Hal ini akan efektif apabila pemerintah setempat terlibat langsung dalam pembinaan (Ratnasari, 2013), sehingga kinerja Koperasi Wanita (kopwan) semakin baik.

Saat ini perkembangan teknologi mempengaruhi kehidupan sehari- hari Triyaningsih, (2012). Perkembangan teknologi yang pesat dewasa ini, menuntut penggunaan sistem manual dikembangkan menjadi sistem komputerisasi (Komara ,2010) agar dapat menyajikan informasi yang cepat dan tepat. Banyak perusahaan atau organisasi yang mulai mengembangkan sistem informasi (Widarno, B, 2012). Dalam pengolahan data, penyimpanan data, ataupun pencacatan setiap transaksi, yang menjadi permasalahan adalah waktu, untuk itu harus digunakan alat-alat untuk mempercepat proses manajemen data (Kandouw, 2013). Penggunaan sistem komputerisasi dengan tujuan untuk mempercepat proses pengolahan data harus dikaji dan dipertimbangkani sejauh mana peran, pengaruh dan manfaat dari sistem akuntansi yang dikomputerisasikan dalam suatu perusahaan. Untuk memenuhi semua itu pemanfaatan komputerisasi sebagai mesin pembantu sudah merupakan suatu kebutuhan, termasuk dalam koperasi (Marsono, 2012).

Di dalam koperasi, juga terdapat kegiatan pengolahan data sepert layaknya 
perusahaan pada umumnya, mulai dari kegiatan pencatatan transaksi sampai pada pelaporan. Perusahaan menghendaki seluruh komponen yang ada dalam organisasi tersebut, mampu bekerja secara efektif dan efisien (Mutiarni, 2016). Seluruh kegiatan tersebut tersebut harus dilakukan secara cepat dan tepat. Untuk itu diperlukan Cara untuk mempercepat pengelolaan data tersebut. Di era digital saat ini, kegiatan pengolahan data bisa ditempuh adalah dengan menggunakan komputer (Indah,2013). Komputerisasi mampu mempermudah pekerjaan manusia (Karmawan et al, 2010) sehingga pengolahan data termasuk di koperasi menjadi lebih cepat dan akurat. Hanya diperlukan sedikit waktu untuk belajar dan berlatih (Karsidi, 2007) dan manfaat yang akan lebih besar akan diperoleh dibandingkan pengorbanan untuk mempelajari sistim pemrosesan data menggunakan data yang lazim dikenal dengan istilah Electronic Data Processing (EDP) (Alannita, et al ,2014).

Pemerintah kabupaten Jombang melaui dinas terkait yaitu Dinas Koperasi dan UMKM Jombang bersama provinsi Jawa Timur memberikan perhatian khusus kepada perkembangan koperasi wanita, antara lain dengan memberikan pelatihan secara berkala kepada pengurus koperasi wanita yang ada di tingkat desa (Suara Mandiri, 2015).

Hal ini bertujuan untuk mencapai misi Dinas Koperasi Dan Usaha Mikro, Kecil Dan Menengah Kabupaten Jombang yaitu meningkatkan kualitas kelembagaan dan usaha Koperasi. Namun, usaha Dinas Koperasi dan UMKM Jombang mengalami beberapa kendala, salah satunya adalah tidak dilaporkannya hasil RAT maupun laporan keuangan tahunan oleh Koperasi (Dinas Koperasi \& UMKM Jombang, 2017)

Salah satu penyebabnya adalah penyusunan dan penyajian laporan keuangan bulanan yang sangat sederhana dan belum memenuhi standar laporan keuangan koperasi dan tidak tepat waktu. Padahal Syarat keberhasilan sebuah koperasi adalah pelaksanaannya sesuai manajemen dan Anggaran Dasar dan Anggaran Rumah Tangga (AD/ART) yang sudah dibuat (Yusuf, 2015). Di Jawa Timur ada 27 ribu koperasi yang aktif dan tiga ribu koperasi tidak aktif, dan sekitar 22 ribu diantaranya telah melaksanakan Rapat Anggota Tahunan/RAT (Yusuf, 2015).

Apabila hal ini terus dibiarkan, maka akan mengganggu kinerja koperasi yang berimbas langsung kepada para anggota. Untuk itu, pengurus koperasi dan pemerintah setempat, dalam hal ini adalah Dinas Koperasi dan Usaha Mikro Kecil dan Menengah (Dinkop Dan UMKM) harus segera mangatasi permasalahan yang umum dihadapi Koperasi Wanita (kopwan) yang ada di desa.

Berdasarkan uraian diatas, maka identifikasi masalah yang diangkat dalam penelitian ini adalah: 1) Mengetahui Sebaran Koperasi Wanita (kopwan) di wilayah kabupaten Jombang yang menerapkan sistim komputerisasi dalam pemrosesan data transaksi (Electronic Data Processing - EDP), 2) Untuk mengetahui penerapan unsur-unsur Electronic Data Processing - EDP $\left(X_{1}\right)$ dan Fakor Pendukung Kesuksesan Pelaksanaan Electronic Data Processing - EDP $\left(X_{2}\right)$ di Koperasi Wanita (kopwan) kabupaten Jombang dan 3) Untuk mengetahui apakah variabel EDP $\left(\mathrm{X}_{4}\right)$ dan Faktor Pendukung Kesuksesan Pelaksanaan Electronic Data Processing - EDP $\left(X_{2}\right)$ berpengaruh terhadap keputusan manajemen Koperasi 


\section{B. LANDASAN TEORI}

Menurut Undang-Undang Republik Indonesia No 25 tahun 1992, Koperasi adalah badan usaha yang beranggotakan orang-seorang atau badan hukum Koperasi dengan melandaskan kegiatannya berdasarkan prinsip Koperasi sekaligus sebagai gerakan ekonomi rakyat yang berdasar atas asas kekeluargaan. Koperasi berbeda dengan badan usaha lainnya, karena kepemilikan koperasi dimiliki oleh seluruh anggota koperasi, sehingga memungkinkan anggota koperasi berkontribusi lebih untuk pengembangan koperasi yang akan berimbas pada kesejahteraan anggotanya.

Permodalan utama koperasi berasal dari anggotanya. Menurut PP 9 Tahun 1995 simpanan adalah dana yang dipercayakan oleh anggota, calon anggota, koperasi lain dan atau anggotanya kepada KSP/USP dalam bentuk tabungan dan simpanan koperasi berjangka (Baswir, 2000). Pengertian simpanan sebagaimana dinyatakan dalam PP tersebut adalah simpanan yang merupakan hutang bagi KSP/USP, sementara itu terdapat jenis simpanan lain dari anggota yang merupakan kekayaan bersih bagi KSP/USP, yaitu simpanan pokok dan simpanan wajib (bagi KSP). Anggota koperasi sebagai pemilik modal berhak untuk mendapat laporan kinerja koperasi yang tercermin dalam laporan keuangan yang dipertanggung jawabkan pada saat Rapat Anggota Tahunan (RAT) yang terdiri dari neraca, perhitungan hasil usaha, laporan arus kas, laporan promosi ekonomi anggota, dan catatan atas laporan keuangan (PSAK No. 27 (Revisi 1998, Reformat 2007). Tentunya, laporan ini akan dapat tersaji dengan benar, cepat dan akurat apabila dibantu oleh sistim komputerisasi yang mendukung kinerja koperasi (Susanti, 2014).

Dalam praktiknya, banyak organisasi yang menggunakan alat bantu komputer untuk mempmudah pengoperasian perusahaan. Penggunaan Komputer dalam suatu organisasi untuk pengolahan data dikenal dengan sebutan Electronic Data Processing (EDP). Electronic Data Processing (EDP) adalah peralatan dan program yang digabungkan menjadi suatu instalasi komputer yang lengkap atau suatu kumpulan program dan prosedur yang berhubungan untuk melaksanakan suatu tugas-tugas tertentu atau tugas yang berkaitan pada suatu computer (Hall, 2001:25)

Pemanfaatan teknologi informasi dan komunikasi (Information and Communication technology-ICT) memberikan potensi untuk meningkatkan produktivitas kerja misalnya dengan membantu pekerja dalam pekerjaan yang bersifat rutinitas sehingga tugas menjadi lebih cepat (Ahuja dan Shankar, 2009; Norton, 1995;. Rodr'iguez Casal et al, 2005; Sigala, 2003). ICT juga dapat digunakan untuk menghilangkan tugas-tugas yang tidak mempunyai nilai tambah sehingga bisa membuat penggunanya menjadi lebih efisien, yang bermuara pada peningkatan kesejahteraan karyawan (Palvalin et al, 2013) Penerapan Electronic DataProcessing (EDP) terbukti bisa meningkatkan efektivitas kinerja karyawan dan pengurus koperasi (Komarasari, 2017) yang akan bermuara pada kemudahan manajemen koperasi dalam mengambil keputusan (Kurniati, 2012).

Marshono (2010) dalam penelitiannya pada koperasi di kabupaten Klaten membuktikan bahwa 76\% responden (karyawan dan pengurus) koperasi menyatakan sangat terbantu dengan sistim komputerisasi pada koperasi (Atikah, 2013). Hal ini juga dibuktikan Susanti pada penelitiannya di Badan Keswadayaan Masyarakat (BKM) Sarana Makmur (2014) yang menyatakan bahwa Sistem informasi simpan pinjam yang berbasis komputer 
dapat membantu bagian Unit Pengelola Keuangan dalam memproses data simpan pinjam menjadi lebih mudah, cepat dan tepat.

Unsur-unsur yang mendukung pelaksanaan pencatatn data secara elektronik (Electronic Data Processing-EDP), selain perangkat alat elektronik, juga harus ada data yang akan diolah. Untuk mengolah data menjadi informasi perlu prosedur-prosedur yang disebut program. Perangkat alat elektronik tersebut sering disebut dengan istilah perangkat keras (hardware), yang dapat berupa layar monitor, printer, mesin CPU, disket, scan plotter, modem, dan sebagainya. Prosedur-prosedur atau program yang digunakan untuk mengolah data disebut perangkat lunak (software), yang terdiri dari: a) Sistem Operasi, yaitu program yang dibuat untuk melakukan dasar- dasar operasi komputer, b) Program Paket yaitu suatu program yang dibuat oleh softwarehouse yang dimaksudkan untuk memudahkan para pemakai dalam melakukan suatu pekerjaan dan c) Program Aplikasi, yaitu suatu prosedur yang dibuat oleh pemrogram untuk mengolah suatu data dalam aplikasi khusus.

Ada beberapa akibat dari diterapkannya Electronic Data Processing (EDP) di suatu organisasi. Sebagai contoh perusahaan akan mengurangi karyawannya karena penerapan EDP ini memungkinkan penyelesaian berbagai aktivitas yang biasa diproses secara manual. Selain itu, penerapan Electronic Data Processing (EDP) juga berdampak pada kualitas laporan keuangan yang dihasilkan dilihat dari: a) Kecepatan Proses, b) Keandalan Laporan, c) Frekuensi Penerbitan Laporan (Irsian, 2015)

Agar suatu sistem yang dikomputerisasi dapat berjalan dengan baik, maka perlu diperhatikan beberapa faktor yang mendukung, yaitu :

1. Kapasitas dan kelengkapan hardware (perangkat keras) yang memadai untuk menangani semua tingkat transaksi dan kebutuhan pemrosesan

2. Software (perangkat lunak) yang merefleksikan dan dapat disesuaikan dengan kebutuhan khusus organisasi

3. Pemrosesan data dan pengawasan perkiraan yang tepat.

4. Dokumentasi yang lengkap mengenai pemakai dan prosedur pengolahan data.

5. Pelatihan yang mencukupi untuk personil pemakai sistem informasi dan petugas pemrosesan data.

6. Masukan (input) yang akurat dan pengawasan untuk menjamin akurasinya.

7. Penerimaan oleh pemakai.

8. Keterlibatan dukungan manajemen (Irsian, 2015)

Dari unsur-unsur yang mendukung adanya EDP, unsur manusia (brainware) adalah unsur yang penting, karena tanpa adanya manusia, perangkat keras maupun perangkat lunak yang canggih pun tidak ada gunanya.

Hal ini karena untuk bisa memanfaatkan teknologi informasi, dibutuhkan Sumber Daya Manusia yang mampu untuk memanfaatkannya (brainware). Karyawan/operator harus disiapkan sebelumnya, agar mempunyai kesiapan teknologi sehingga bisa mengaplikasikannya untuk kepentingan organisasi. Dengan kombinasi sistim informasi yang berkualitas dan Sumber Daya Manusia yang tanggap teknologi maka akan tercipta kinerja organisasi yang baik akan tercipta (Kuo, 2012). Agar karyawan bisa menjalankan program berbasis teknologi informasi (komputerisasi) diperlukan pelatihan 
untuk meningkatkan kemampuan yang diperlukan untuk peningkatan kualitas layanan, sehingga tercapai tujuan organisasi (Hafsah, 2015) serta mempermudah proses pengambilan keputusan oleh manajemen organisasi, yang pada saat ini sangat cepat berubah. Proses pengambilan keputusan yang cepat dan tepat dilakukan agar roda organisasi beserta administrasi dapat berjalan terus dengan lancar. Pengambilan keputusan adalah suatu pendekatan sistematis terhadap suatu masalah, pengumpulan fakta dan data, penelitian yang matang atas alternatif dan tindakan (Subari dan Tata, 2003). Pengambilan keputusan tidak terjadi secara tiba-tiba, melainkan melalui sebuah proses. Menurut Drucer, proses pengambilan keputusan terdiri atas: 1) Menetapkan masalah,

2) Manganalisa masalah, 3) Mengembangkan alternatif, 4) Mengambil keputusan yang tepat, 5) Mengambil keputusan menjadi tindakan efektif (Subari, Tata, 2003)

\section{Metode Penelitian}

Penelitian ini dilakukan di Koperasi Wanita (kopwan) Jombang yang terdiri dari 21 kecamatan yang tersebar di 301 desa dan 5 kelurahan termasuk jenis penelitian kualitatif, yaitu jenis penelitian yang temuan-temuannya tidak diperoleh melalui prosedur statistik atau bentuk hitungan lainnya yang bertujuan untuk memahami obyek yang diteliti secara mendalam.

Data yang digunakan dalam penelitian ini adalah: 1) Data Primer: yaitu data yang bersumber langsung dari responden, yang diperoleh melalui jawaban atas pernyataan yang diajukan dalam kuisioner, dan 2) Data Sekunder: yaitu data yang diperoleh dari Puskopwan dan Dinas Koperasi \& UMKM Jombang, serta berbagai literatur yang berhubungan dengan penelitian.

Untuk mendapatkan data yang akan dianalisis, digunakan 2 (dua) metode yaitu: 1) Kuisioner (angket) yaitu sejumlah pertanyaan yang diajukan kepada responden yang berisi 4 (empat) opsi jawaban tertutup seputar pertanyaan yang diberikan mulai dari sangat setuju hingga sangat tidak setuju, 2) Wawancara dengan responden dan pegawai Dinas Koperasi dan UMKM kabupaten Jombang, dan 3) Dokumentasi dengan cara menggali informasi yang tertulis atau tercetak yang dapat dipakai sebagai bukti keterangan yang berhubungan dengan penelitian yang dilakukan, baik itu catatan-catatan atau dokumen-dokumen yang berhubungan dengan Koperasi Wanita (kopwan) di kabupaten Jombang.

Populasi sekaligus dalam penelitian ini adalah Koperasi wanita (kopwan) di wilayah kabupaten Jombang. Teknik sampling menggunakan rumus Slovin (Sevilla et. al, 2017:182). Maka berdasarkan jumlah populasi Koperasi Wanita (kopwan) di kabupaten Jombang yaitu sejumlah 306 Koperasi Wanita (kopwan), maka sampel yang terlibat dalam penelitian ini adalah 155 Koperasi Wanita (kopwan) yang menjadi anggota. Dari 155 Koperasi Wanita (kopwan) masih dipilah lagi menjadi Koperasi Wanita (kopwan) yang aktif (telah melakukakn Rapat Anggota Tahunan-RAT) dan yang tidak aktif (belum melakukakan Rapat Anggota Tahunan-RAT).

Hasilnya didapat 90 Koperasi Wanita (kopwan) yang layak untuk menjadi responden dalam penelitian ini. Selanjutnya, dari 90 responden, masih direduksi lagi berdasarkan sistim pencatatan transaksinya, menggunakan cara manual atau komputerisasi. 
Selanjutnya di lakukan pengamatan atas variabel yang diteliti yaitu:

\section{Tabel 1. Operasioanlisasi Variabel}

\begin{tabular}{|c|c|c|}
\hline Varaiabel & Sub Variabel & Operasionalisasi Variabel \\
\hline \multirow[t]{3}{*}{$\begin{array}{l}\text { Electronic } \\
\text { Processing } \\
\left(\mathbf{X}_{1}\right)\end{array}$} & Perangkat keras (hardware) $\left(\mathrm{X}_{1.1}\right)$ & $\begin{array}{l}\text { Seperangkat alat elektronik yang } \\
\text { terdiri dari layar monitor, printer, mesin } \\
\text { CPU, dan media penyimpanan eksternal }\end{array}$ \\
\hline & $\begin{array}{l}\text { perangkat lunak (software) } \\
\left(\mathrm{X}_{1.2}\right)\end{array}$ & $\begin{array}{l}\text { Prosedur-prosedur atau program } \\
\text { yang digunakan untuk mengolah data }\end{array}$ \\
\hline & Data $\left(\mathrm{X}_{1 \cdot 3}\right)$ & $\begin{array}{l}\text { Sekumpulan informasi yang } \\
\text { mencerminkan kegiatan transaksi di } \\
\text { Koperasi Wanita (kopwan) }\end{array}$ \\
\hline \multirow{5}{*}{$\begin{array}{l}\text { Faktor Pendukung } \\
\text { suksesnya } \\
\text { pelaksanaan EDP } \\
\text { (X2) }\end{array}$} & Dokumen $\left(\mathrm{X}_{2 \cdot 1}\right)$ & $\begin{array}{l}\text { Dokumentasi yang lengkap } \\
\text { mengenai pemakai dan prosedur } \\
\text { pengolahan data }\end{array}$ \\
\hline & Pelatihan $\left(\mathrm{X}_{2.2}\right)$ & $\begin{array}{l}\text { Pelatihan yang mencukupi untuk } \\
\text { personil pemakai sistem informasi } \\
\text { dan petugas pemrosesan data. }\end{array}$ \\
\hline & Akurasi masukan $\left(\mathrm{X}_{2.3}\right)$ & $\begin{array}{l}\text { Masukan (input) yang akurat dan } \\
\text { pengawasan untuk menjamin } \\
\text { akurasinya. }\end{array}$ \\
\hline & $\operatorname{Kesediaan}\left(\mathrm{X}_{2 \cdot 4}\right)$ & Penerimaan oleh pemakai \\
\hline & Dukungan $\left(\mathrm{X}_{2.5}\right)$ & $\begin{array}{l}\text { Keterlibatan dukungan dari pengelola } \\
\text { Koperasi Wanita (kopwan) dan dinas } \\
\text { terkait }\end{array}$ \\
\hline \multirow{4}{*}{$\begin{array}{l}\text { Keputusan } \\
\text { Manajemen } \\
(\mathbf{Y})\end{array}$} & $\begin{array}{l}\text { Keteraturan jadwal Pencairan } \\
\text { Pinjaman }\left(\mathrm{Y}_{1}\right)\end{array}$ & $\begin{array}{l}\text { Ketepatan jadwal pencairan pengajuan } \\
\text { piutang anggota }\end{array}$ \\
\hline & $\begin{array}{l}\text { Kemudahan pengecekan data } \\
\text { keuangan anggota }\left(\mathrm{Y}_{2}\right)\end{array}$ & $\begin{array}{l}\text { Kemudahan pengurus Koperasi Wanita } \\
\text { (kopwan) untuk mengecek data } \\
\text { tabungan dan pinjaman anggota di } \\
\text { Koperasi Wanita (kopwan) }\end{array}$ \\
\hline & $\begin{array}{l}\text { Kemudahan Penyusunan Laporan } \\
\text { Keuangan (Y3) }\end{array}$ & $\begin{array}{l}\text { Kemudahan penyusunan laporan SHU } \\
\text { berjalan, neraca berjalan dan aliran kas } \\
\text { Koperasi Wanita (kopwan) }\end{array}$ \\
\hline & $\begin{array}{l}\text { Keteraturan jadwal Pelaporan } \\
\text { Keuangan ke Puskopwan dan } \\
\text { DInas Koperasi dan UMKM }\left(\mathrm{Y}_{4}\right) \\
\text { Ketepatan jadwal penyelenggaraan } \\
\text { Rapat Anggota Tahunan (RAT) } \\
\left(\mathrm{Y}_{5}\right)\end{array}$ & $\begin{array}{l}\text { Keteraturan dan ketepatwaktuan jadwal } \\
\text { pelaporan keuangan ke Puskopwan dan } \\
\text { Dinas Koperasi dan UMKM Jombang } \\
\text { Keteraturan dan ketepatwaktuan jadwal } \\
\text { penyelenggaraan RAT yaitu pada bulan } \\
\text { Januari - Maret }\end{array}$ \\
\hline
\end{tabular}

\section{HASIL DAN PEMBAHASAN}

Gambaran Umum Koperasi Wanita (kopwan) di Jombang

Kabupaten Jombang terdiri dari 21 Kecamatan yang terdiri dari 301 desa dan 5 (lima) kelurahan. Tiap desa memiliki Koperasi Wanita (Kopwan), seperti yang tampak pada tabel berikut: 
Tabel 2. Data sebaran Koperasi Wanita (Kopwan) di Kabupaten Jombang

\begin{tabular}{rlc}
\hline No & Nama & Jumlah \\
\hline 1 & Mojowarno & 19 \\
2 & Bareng & 13 \\
3 & Bandar Kedung Mulyo & 11 \\
4 & Kesamben & 14 \\
5 & Ngusikan & 11 \\
6 & Jogoroto & 11 \\
7 & Kudu & 11 \\
8 & Kabuh & 16 \\
9 & Perak & 13 \\
10 & Diwek & 20 \\
11 & Mojoagung & 18 \\
12 & Sumobito & 21 \\
13 & Plandaan & 13 \\
14 & Peterongan & 14 \\
15 & Tembelang & 15 \\
16 & Jombang & 20 \\
17 & Ngoro & 13 \\
18 & Gudo & 18 \\
19 & Wonosalam & 9 \\
20 & Megaluh & 13 \\
21 & Ploso & 13 \\
\hline Jumlah & \multicolumn{2}{c}{306} \\
\hline
\end{tabular}

Sumber: Dinas Koperasi dan UMKM Jombang, 2017

Akan tetapi, dari 306 Koperasi Wanita (Kopwan) di Kabupaten Jombang, tidak semuanya aktif dan dapat melakukan Rapat Anggota Tahunan (RAT). Dari data yang diperoleh dari Dinas Koperasi dan UMKM Kabupaten Jombang, diketauhi bahwa sampai dengan Juni 2017, ada 236 atau 77\% Koperasi Wanita (Kopwan) yang bisa menyelenggarakan RAT, sedangkan sisanya yaitu, 70 Koperasi Wanita (Kopwan) atau 23\% dari total Koperasi Wanita (Kopwan) di Jombang, tidak atau belum melakukan RAT seperti yang tampak pada tabel berikut:

Tabel 3. Jadwal Penyelenggaraan Rapat Anggota Tahunan (RAT)

Koperasi Wanita (Kopwan) Jombang Tahun 2017

\begin{tabular}{lrr}
\hline \multicolumn{1}{c}{ Bulan } & $\begin{array}{c}\text { Jumlah } \\
\text { Kopwan }\end{array}$ & Prosentase \\
\hline Januari & 87 & $28 \%$ \\
Pebruari & 69 & $23 \%$ \\
Maret & 49 & $16 \%$ \\
April & 17 & $6 \%$ \\
Mei & 12 & $4 \%$ \\
Juni & 2 & $1 \%$ \\
Tidak/Belum RAT & 70 & $23 \%$ \\
Jumlah & $\mathbf{3 0 6}$ & $\mathbf{1 0 0 \%}$ \\
\hline
\end{tabular}

Sumber: Dinas Koperasi dan UMKM Jombang, 2017 
Dari tabel diatas, apabila digambarkan dalam bentuk diagram lingkaran, akan tampak seperti gambar berikut:

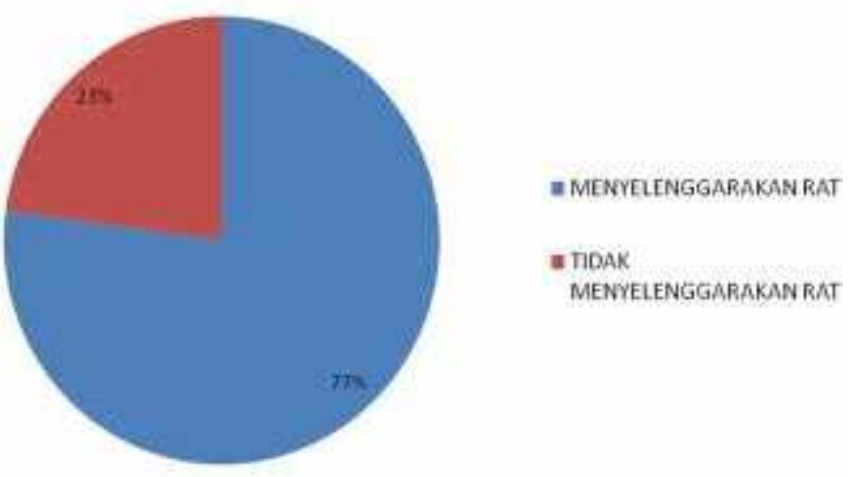

\section{Gambar 1. Perbandingan Koperasi Wanita (Kopwan) Yang Menyelenggarakan RAT Tahun 2017}
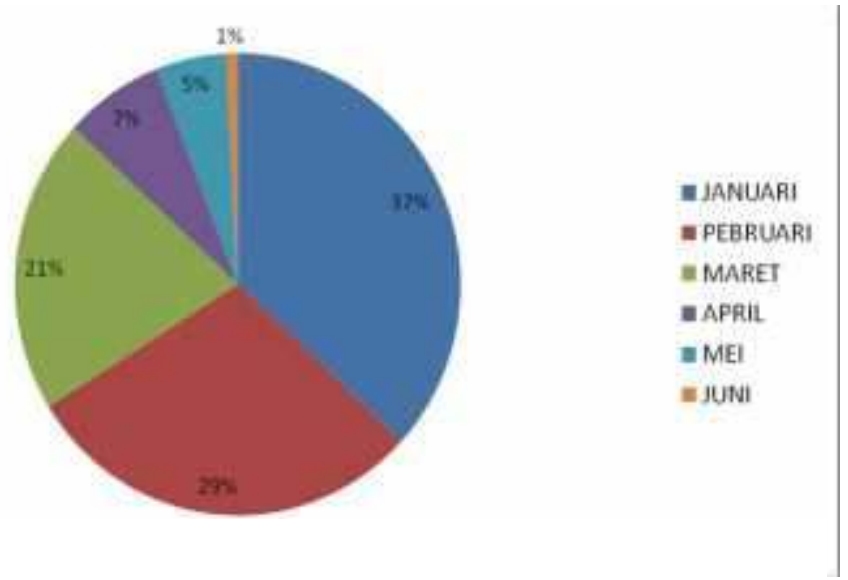

\section{Gambar 2. Bulan Penyelenggaraan RAT}

Dari gambar tersebut diatas tampak bahwa dari 206 Koperasi Wanita (Kopwan) di Jombang yang melakukan RAT, tidak semuanya mampu menyelenggarakan secara tepat waktu atau 2 (dua) bulan pertama di awal tahun. Sebanyak 66\% mampu menyelenggarak di bulan Januari dan Pebruari, sedangkan sisanya melakukan RAT di antara bulan Maret sampai Juni 2017.

Rumusan masalah yang pertama pada penelitian ini adalah untuk mengetahui sebaran Koperasi Wanita (kopwan) di Jombang yang menggunakan sistim pencatatan transaksi secara komputerisasi. Dari hasil kuisioner yang disebar melalui angket kepada responden yang menjadi sampel dalam penelitian ini, diperoleh hasil sebagai berikut: 
Tabel 4. Sebaran Koperasi Wanita (Kopwan) Yang Menggunakan Sistim Pencatatan Komputerisasi

\begin{tabular}{|c|c|c|c|}
\hline No & Keterangan & Jumlah & Prosentase \\
\hline 1 & $\begin{array}{l}\text { Menggunakan Sistim } \\
\text { Komputerisasi }\end{array}$ & 19 Koperasi Wanita (Kopwan) & $21 \%$ \\
\hline 2 & $\begin{array}{l}\text { Tidak Menggunakan } \\
\text { Sistim Komputerisasi }\end{array}$ & 71 Koperasi Wanita (Kopwan) & $79 \%$ \\
\hline \multicolumn{2}{|c|}{ Total Responden } & 90 Koperasi Wanita (Kopwan) & $100 \%$ \\
\hline
\end{tabular}

Sumber: Data Primer Diolah, 2017

Dari tabel tersebut diatas, tampak bahwa mayoritas Koperasi Wanita (Kopwan) di Jombang tidak menggunakan pencatatan secara komputerisasi. Mayoritas Koperasi Wanita (Kopwan) masih menggunakan pencatatan secara manual.

Dari hasil pengamatan lebih lanjut, diketahui bahwa dari 19 Koperasi Wanita (Kopwan) yang menyatakan menggunakan sistim komputerisasi dalam pencatatan transaksi harian masih dikategorikan dalam 2 (dua) kelompok yaitu:

1. Menggunakan Program Sistim informasi Koperasi Simpan Pinjam dalam setiap pencatatan transaksi. Hanya ada 1 (satu) Koperasi Wanita (Kopwan) yaitu Koperasi Wanita (Kopwan) Bunga Harapan di Desa Ceweng Kecamatan Diwek.

2. Menggunakan Alat bantu Ms. Excel dalam pencatatan transaksi harian hingga penyusunan laporan keuangan. Ada 18 Koperasi Wanita (Kopwan) yang termasuk dalam kelompok ini.

Untuk kelompok ini, juga dibagi menjadi 2 (dua) kelompok yaitu: 1) Menggunakan Ms. Excel mulai dari pencatatan transakasi, pemostingan ke buku besar dan buku besar pembantu, hingga penyusunan laporan keuangan; serta 2) Menggunakan Ms. Excel untuk penyusunan laporan keuangan tahunan sebagai dasar penyelenggaraan Rapat Anggota Tahunan (RAT).

Sebaran Koperasi Wanita (Kopwan) Di Jombang Yang Menggunakan Electronic Data Processing Dalam Pencatatan Transaksinya

Dari hasil penelitian, diketahui bahwa dari 306 Koperasi Wanita (kopwan) yang ada di Jombang, hanya 19 Koperasi Wanita (kopwan) atau kurang lebih 6\% yang menggunakan sistim pencatatan transaksi secara komputerisasi. Hal ini tentu kurang jika dibanding dengan jumlah Koperasi Wanita (kopwan) yang ada. Kenyataan ini juga sekaligus menjadi pekerjaan rumah bagi instansi terkait di Jombang, yaitu Puskopwan dan Dinas Koperasi dan UMKM sebagaimana yang tersebut dalam visi, misi dan tugas pokok dan fungsi dari Dinas Koperasi dan UMKM Jombang, yaitu : terwujudnya koperasi berkualitas dan UMKM yang tangguh serta berdaya saing (Dinkop \& UMKM Jombang, 2017)

Hal ini tentu menjadi kendala yang harus diselesaikan karena di era globalisasi dan komputerisasi saat ini, diperlukan kehandalan dalam pengelolaan koperasi agar bisa berkualitas (Dinkop \& UMKM Jombang, 2017)

Penerapan Unsur-Unsur Electronic Data Processing (EDP) Di Koperasi Wanita (Kopwan) Kabupaten Jombang

Dari hasil penelitian diketahui bahwa penerapan penerapan Electronic Data Processing (EDP) di Koperasi Wanita (kopwan) kabupaten Jombang sudah baik. Seluruh responden 
menyatakan bahwa agar pelaksanaan Electronic Data Processing - EDP bisa berhasil, diperlukan dukungan dari sisi hardware, software yang cukup. Hal ini sesuai dengan penelitian yang dilakukan Chrystanti (2011), Alannita dan Suaryana, I (2014). Selain itu, juga diperlukan data yang akurat dan rinci agar proses pemasukan data hingga penyajian laporan bisa akurat. Hal ini sesuai dengan penelitian yang dilakukan oleh Atikah (2013).

Penerapan Fakor Pendukung Kesuksesan Pelaksanaan Electronic Data Processing (EDP) Di Koperasi Wanita (Kopwan) Kabupaten Jombang

Dari hasil penelitian diketahui bahwa Penerapan Fakor Pendukung Kesuksesan Pelaksanaan Electronic Data Processing - EDP di Koperasi Wanita (kopwan) kabupaten Jombang juga sudah dilakukan dengan baik. Seluruh responden menyatakan bahwa Pelaksanaan Electronic Data Processing - EDP tidak akan berhasil dengan baik, tanpa dukungan dari factor-faktor lain yaitu dokumen, kesediaan, dukungan, akurasi masukan. Hal ini sesuai dengan penelitian Asnur (2015). Pelatihan pada koperasi Pelatihan adalah hal yang sangat ditunggu dan diharapkan oleh para pengurus Koperasi Wanita (kopwan) karena hal tersebut akan mampu meningkatkan kemampuan pengurus untuk menggunakan perangkat Electronic Data Processing (Dinas Koperassi dan UMKM Jombang, 2017). Hal ini sesuai dengan penelitian Faidah dan Dewi (2014).

Dari hasil penelitian diketahui bahwa Koperasi Wanita (kopwan) yang melakukan pencatatan transaksi dengan system komputerisasi bisa melakukan pengecekan, pelaporan hingga pengambilan keputusan manajemen dengan mudah (Kurniawan, 2015). Hal ini terbukti dari laporan keuangan yang bisa disusun dengan rapi dan rinci hingga jadwal pelaksanaan Rapat Anggota Tahunan tepat waktu (Arifin et al, 2015).

\section{E. PENUTUP}

Dari hasil penelitian dan pembahasan yang telah disampaikan bisa disimpulkan beberapa hal. Pertama, Dari 306 Koperasi Wanita (kopwan) yang tersebar di 21 kecamatan di kabupaten Jombang, tidak semuanya dalam kondisi aktif. Dari hasil penelitian diketahui bahwa untuk tahun 2017, sebanyak 70 Koperasi Wanita (kopwan) atau 23\%, sampai bulan Juni, belum melakukan Rapat Anggota Tahunan (RAT). Dari 236 Koperasi Wanita (kopwan) yang tercatat aktif di Dinas Koperasi dan UMKM kabupaten Jombang, tidak seluruhnya menggunakan sistim pencatatan transaksi secara komputerisasi. Diketahui bahwa 19 Koperasi Wanita (kopwan) yang menggunakan komputer untuk membantu pencatatan transaksinya. Dari 19 Koperasi Wanita (kopwan) yang menggunakan sistim komputerisasi dalam pencatatan transaksi harian masih dikategorikan dalam 2 (dua) kelompok yaitu: 1) Menggunakan Program Sistim informasi Koperasi Simpan Pinjam dalam setiap pencatatan transaksi. Hanya ada 1 (satu) Koperasi Wanita (Kopwan) yaitu Koperasi Wanita (Kopwan) Bunga Harapan di Desa Ceweng Kecamatan Diwek, 2) Menggunakan Alat bantu Ms. Excel dalam pencatatan transaksi harian hingga penyusunan laporan keuangan.

Kedua, penerapan Electronic Data Processing (EDP) serta Penerapan Fakor Pendukung Kesuksesan Pelaksanaan Electronic Data Processing - EDP di Koperasi Wanita (kopwan) kabupaten Jombang sudah baik. 
Ketiga, variabel Electronic Data Processing dan Faktor Pendukung Kesuksesan Pelaksanaan Electronic Data Processing berpengaruh terhadap keputusan manajemen Koperasi. Dari hasil penelitian diketahui bahwa Koperasi Wanita (kopwan) yang melakukan pencatatan transaksi dengan system komputerisasi bisa melakukan pengecekan, pelaporan hingga pengambilan keputusan manajemen dengan mudah. Selain itu, dengan penggunaan Electronic Data Processing dalam pencatatan transaksi harin, laporan keuangan bisa disusun dengan rapi dan rinci sehingga jadwal pelaksanaan Rapat Anggota Tahunan tepat waktu.

Maka berangkat dri simpulan diatas, disarankan kepada Puskopwan dan Dinas Koperasi \& UMKM Jombang hendaknya memantau dan bertindak proaktif terhadap Koperasi Wanita (kopwan) di Jombang, terutama kepada Koperasi Wanita (kopwan) yang terdeteteksi belum menyelenggarakan Rapat Anggota Tahunan hingga bulan yang ditentukan oleh Puskopwan ataupun Dinas Koperasi \& UMKM Jombang.

Puskopwan ataupun Dinas Koperasi \& UMKM Jombang hendaknya mengadakan pelatihan tentang pencatatan transaksi secara komputerisasi atau Electronic Data Processing (EDP) transaksi harian, mengingat jumlah Koperasi Wanita (kopwan) di Jombang yang menerapkan Electronic Data Processing (EDP) transaksi harian hanya 6\%. Hal ini perlu ditingkatkan jumlahnya agar memudahkan pengurus Koperasi Wanita (kopwan) dalam pengambilan keputusan manajemen koperasi

\section{DAFTAR PUSTAKA}

Ahuja, V, Shankar, J. 2009, “Benefits Of Collaborative Ict Adoption For Building Project Management', Construction Innovation: Information, Process, Management, VOL. 9 No. 3, PP. 323-340.

Alannita, N. P., \& Suaryana, I. G. N. A. (2014). Pengaruh Kecanggihan Teknologi Informasi, Partisipasi Manajemen, Dan Kemampuan Teknik Pemakai Sistem Informasi Akuntansi Pada Kinerja Individu. E-Jurnal Akuntansi, 33-45.

Arifin, S., Mawardi, A. I., \& Buchori, I. (2015). Pendampingan Akses Pembiayaan Koperasi Wanita Dalam Rangka Fasilitasi Perkuatan Permodalan: Kabupaten Sumenep, Kabupaten Sidorajo, Dan Kota Surabaya.

Atikah, H. R. (2013). Sistem Informasi Simpan Pinjam Pada Koperasi Wanita Putri Harapan Desa Jatigunung Kecamatan Tulakan. EPUB-SISTEM INFORMASI, 1(1).

Asnur, D. (2015). Penyusunan Instrumen Dan Pembangunan Sistem Informasi Data Dasar Koperasi Dan UKM Terpilih. Jurnal Pengkajian KUKM, 5(1)

Baswir, R. (2000). Koperasi Dan Kekuasaan Dalam Era Orde Baru.

Budhiretnowati, G., \& Siahaan, R. (2015). Menggerakkan Denyut Nadi Koperasi Wanita Dalam Menghadapi Era Globalisasi. INFOKOP, 15(1)

Chrystanti, Y. C. (2011). Sistem Pengolahan Data Simpan Pinjam Khusus Perempuan (SPP) Pada Unit Pengelola Kegiatan (UPK) Mitra Usaha Mandiri Program Nasional Pemberdayan Masyarakat Mandiri Perdesaan (PNPM-Mpd) Kecamatan Pringkuku Kabupaten Pacitan Yulanita 
Hafsah, M. J. (2015). Upaya Pengembangan Usaha Kecil Dan Menengah (UKM). INFOKOP, 12(25).

Hall, James. 2007. Sistem informasi akuntansi. Jakarta : Salemba Empat.

Husein, Umar, 2008, "Metode Penelitian Untuk Skripsi dan Tesis Bisnis", Jakarta, PT

Rajagrafindo Persada

Indah, I. N. (2013). Pembuatan Sistem Informasi Penjualan Pada Toko Sehat Jaya Elektronik Pacitan. Speed-Sentra Penelitian Engineering Dan Edukasi, 12(1).

Faidah, S. N., \& Dewi, R. M. (2014). Penerapan Sistem Tanggung Renteng Sebagai Upaya Mewujudkan Partisipasi Aktif Anggota Dan Perkembangan Usaha Di Koperasi Wanita Setia Bhakti Wanita Jawa Timur. Jurnal Pendidikan Ekonomi (JUPE), 2(3).

Irsian, Rudy, 2015, "Penerapan Electronic Data Processing Dalam Sistem Informasi Akuntansi Pada PT. Mediadata Corp", e-jurnal.uda.ac.id

Kandouw, V. M. (2013). Evaluasi Sistem Informasi Akuntansi Penerimaan Kas Pada PT Catur Sentosa Adiprana Cabang Manado. Jurnal riset ekonomi, manajemen, bisnis dan akuntansi, 1(3).

Karmawan, I. G. M., sundjaja, a. M., \& luhukay, d. (2010, june). Analisis dan perancangan e-commerce pd. Garuda jaya. In seminar nasional aplikasi teknologi informasi (snati).

Karsidi, R. (2007). Pemberdayaan Masyarakat Untuk Usaha Kecil Dan Mikro (Pengalaman Empiris Di Wilayah Surakarta Jawa Tengah). Jurnal Penyuluhan, 3(2).

Kuo, Yen-Lin, 2012, "Technology Readiness As Moderator For Construction Company Performance, Industrial Management \& Data Systems”, Vol. 113 No. 4, 2013 pp.558-572 Emerald Group Publishing Limited, 0263-5577

Kurniawan, D. (2015). Analisis Kinerja Koperasi Berdasarkan Peraturan Menteri Negara Koperasi Dan Usaha Kecil Dan Menengah Republik Indonesia Nomor: 06/Per/M. Kukm/V/2006 (Studi Kasus Pada Koperasi Karyawan PT Gudang Garam, Tbk "MEKAR" Kediri Periode 2011-2013). Jurnal Administrasi Bisnis, 27(1).

Komara, a. (2010). Analisis Faktor-Faktor Yang Mempengaruhi Kinerja Sistem Informasi Akuntansi. Jurnal manajemen, akuntansi \& sistem informasi, 6(2), 143-160.

Komarasari, W. (2017). Pengaruh Kapasitas Sumber Daya Manusia, Pemanfaatan Teknologi Informasi Dan Pengendalian Intern Akuntansi Terhadap Keterandalan Pelaporan Keuangan Daerah (Pada SKPD Kabupaten Bantul Bagian Akuntansi Dan Keuangan). Prodi Akuntansi UPY.

Kurniati, I. (2012). Analisis Dan Perancangan Sistem Informasi Akuntansi Piutang Usaha Terkomputerisasi Pada Primer Koperasi Kepolisian Korps Brimob (Primkoppol Korps Brimob)

Marshono, Shandy, Jumadi (2010), "Implementasi Akuntansi Berbasis Komputer Pada Koperasi Di Kabupaten Klaten”, e-journal.stie-aub.ac.id

Miikka Palvalin, Antti lo" nnqvist and Maiju Vuolle, 2013, "Analysing The Impacts Of Ict On Knowledge Work Productivity”, Journal of Knowledge Management, Vol. 17 no. 4, pp. 545-557, Emerald Group Publishing Limited, ISSN 13673270 
Mutiarni, R. (2016). EFEKTIVITAS PEMBELAJARAN MICROSOSFT EXCEL BERBASIS INTERAKTIF PADA MATA KULIAH TEKNOLOGI INFORMASI DAN KOMUNIKASI (TIK)(Study Kasus Pada Mahasiswa Manajemen STIE PGRI Dewantara Jombang). Eksis: Jurnal Riset Ekonomi dan Bisnis, 11(2 Okt).

Partomo, Sartika Titik, 2009, Ekonomi Koperasi, Edisi 1, Ghalia Indonesia. PSAK no.27, Revisi 1998, Reformat 2007, Tahun 2009 Paragraf Kesembilan.

Ratnasari, D. D. (2013). Optimalisasi Peran Koperasi Wanita Dalam Meningkatkan Kesejahteraan Anggota (Studi Pada Koperasi Wanita Potre Koneng Kabupaten Sumenep). Jurnal Administrasi Publik, 1(3), 51-60.

Ratnasari, Deasy, Saleh Choirul, Rozikin, 2012, "Optimalisasi Peran Koperasi Wanita Dalam Meningkatkan Kesejahteraan Anggota", Jurnal Administrasi Publik Vol1, no 3 (2013) page. 51-60, Fakultas Ilmu Administrasi, Universitas Brawijaya.

Subari, Tata. 2003. SistemInformasiManajemen. Andi.Yogyakarta.

Sigala, M, 2003, "The Information And Communication Technologies Productivity Impact On The Uk Hotel Sector', International Journal Of Operations \& Production Management, Vol. 23 no. 10, pp. 1224-1245.

Sevilla, Consuelo G. et. al (2007). Research Methods. Rex Printing Company. QuezonCity.

Susanti, Nanik, 2014, "Sistem Informasi Simpan Pinjam Badan Keswadayaan Masyarakat Studi Kasus BKM Sarana Makmur", Jurnal Simetris, Vol 5 No 1 A pril 2014, ISSN:2252-4983

Tartini \& Zulkifli, 2016. Pelatihan Dan Pendampingan Koperasi Serba Usaha. Eksis: Jurnal Riset Ekonomi dan Bisnis, Oktober, Volume 11, pp. 151-164.

Triyaningsih, S. L. (2012). Dampak Online Marketing Melalui Facebook Terhadap Perilaku Konsumtif Masyarakat. Ekonomi dan kewirausahaan, 11(2).

Widarno, B. (2012). Efektivitas Perencanaan Dan Pengembangan Sistem Informasi. Akuntansi, 6(1).

Yuni Nurmawati, Y. (2015). Pengaruh Jumlah Anggota, Jumlah Simpanan, Jumlah Pinjaman Dan Jumlah Modal Kerja Terhadap Sisa Hasil Usaha (SHU) Pada Koperasi Simpan Pinjam (KSP) Yang Bernaung Di Bawah Dinas Koperasi Dan UMKM Kabupaten Kulon Progo Tahun 2011-2014 (Doctoral Dissertation, Fakultas Ekonomi).

Yusuf, S. (2015, mei 27). Http://suaramandiri.com. Retrieved mei 18, 2017, from suara mandiri web site: http://suaramandiri.com/peristiwa/item/3616-34-koperasi-di-jatimdidominasi-kopwan

Zakaria, M. (2016, pebruari 4). Majalah suara pendidikan. Retrieved mei 21, 2017, from majalah suara pendidikan web site: http://majalahsuarapendidikan.net/koperasiwanita-semakin-berdaya 